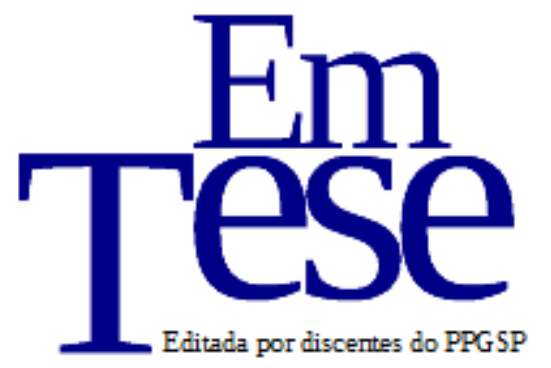

UFSC

PPG SP PROG RAMA DE

PÓS-GRADUAÇÃO EM

Sociologia

Política

v. 15, n. 1 (parte II), p.33-48, mar./abr., 2018.

http://dx.doi.org/10.5007/1806-5023.2018v15n1p33

\title{
I Congresso Brasileiro da Indústria: momento de consolidação das ideias de Roberto Simonsen como parte da ideologia da burguesia industrial brasileira ${ }^{1}$
}

Moacir de Freitas Junior ${ }^{2}$

Resumo: O presente trabalho tem o objetivo de debater a hipótese de que as ideias defendidas pelo intelectual e empresário Roberto Simonsen foram assimiladas pelo grupo industrialista e tornaram-se parte da dinâmica de construção de um pensamento dos industriais brasileiros da época, sendo o momento desta convergência a realização do I Congresso Brasileiro da Indústria, em 1944. Para tanto, partimos da análise dos Anais do I Congresso Brasileiro da Indústria, analisamos as propostas aprovadas e os discursos apresentados pelas autoridades presentes, bem como apresentamos em parte as obras e ideias de Simonsen, demonstrando como tais questões deixaram de ser parte de seu leque de pensamentos para integrar a base ideológica da então classe industrial brasileira.

Palavras-chave: Simonsen; classe industrial; I Congresso; hegemonia

I Brazilian Congress of Industry: moment of consolidation of the ideas of Roberto Simonsen as part of the ideology of the Brazilian industrial bourgeoisie

\begin{abstract}
The present work has the objective of discussing the hypothesis that the ideas defended by the intellectual and entrepreneur Roberto Simonsen were assimilated by the industrialist group and became part of the dynamics of construction of a thought of the Brazilian industrialists of the time, being the moment of this convergence to The First Brazilian Congress of Industry, we analyzed the approved proposals and the speeches presented by the present authorities, as well as presenting in part the works and ideas of Simonsen, demonstrating how These questions ceased to be part of their range of thoughts to integrate the ideological base of the then Brazilian industrial class.
\end{abstract}

Keywords: Simonsen; industrial class; I Congress 
O presente trabalho tem o objetivo de debater a hipótese de que as ideias defendidas pelo intelectual e empresário Roberto Simonsen foram assimiladas pelo grupo industrialista e tornaram-se parte da dinâmica de construção de um pensamento dos industriais brasileiros da época, sendo o momento desta convergência a realização do I Congresso Brasileiro da Indústria, em 1944. Simonsen, uma das mais importantes lideranças política dos industriais brasileiros do período, era formulador e defensor de ideias para o desenvolvimento do Brasil, advogando que a industrialização era a única forma capaz de fazer avançar o ciclo de desenvolvimento nacional.

Durante sua vida, Simonsen elaborou e divulgou seus pensamentos sobre o Brasil, teses estas que, em alguma medida, confundem-se com as das entidades por ele presididas e de outras que, apesar de não dirigidas por ele diretamente, encamparam este conjunto de ideias que acabou por representar um pensamento, um plano de ação do segmento industrial para Brasil.

Nesta linha, o I Congresso Brasileiro da Indústria aprovou mais de 130 teses sobre os mais variados temas relacionados à indústria e ao seu papel no desenvolvimento nacional, o que levanta a hipótese de que os industriais brasileiros disputaram politicamente sua ascensão e hegemonia com base em um conjunto amplo de ideias que dotou este segmento de uma certa unidade política e ideológica que foram fundamentais para os resultados políticos alcançados. Parte importante delas, como veremos, foram elaboras por Simonsen.

Para este trabalho, nossa intenção é apresentar estas teses e seus formuladores, analisar os debates que as envolveram e estão registrados nos Anais do I Congresso Brasileiro da Indústria. Pretendemos verificar os discursos proferidos durante os trabalhos, que contaram com a presença do próprio Getúlio Vargas, dando mostra do quanto os industriais avançaram politicamente sobre o Estado entre 1930 e 1940. Com isso, pretendemos demonstrar a hipótese aqui fomentada, de que as ideias formuladas por Simonsen foram assimiladas pela burguesia industrial brasileira e tornaram-se seu plano de ação na disputa pela hegemonia economia e política do Brasil na época.

\section{Roberto Simonsen: um intelectual da burguesia industrial brasileira}

Simonsen foi um empresário e intelectual que se tornou um dos maiores líderes da burguesia industrial do Brasil da primeira metade do século XX. Foi, em grande parte, graças às suas ações que os industriais atuaram buscando influenciar a política econômica da época. Sua ascensão como pensador e líder de sua classe se deu ao mesmo tempo em que no Brasil ocorria, especialmente a partir da década de 1930, a implantação do capitalismo industrial, o fortalecimento do Estado como fator decisivo para a industrialização e, consequentemente, a chegada da burguesia nacional ao poder, para os quais contribuiu diretamente. 
Foi também nesse mesmo contexto histórico (as três principais décadas, de 1910 a 1940, em que ocorreram transformações sociais, econômicas e políticas que marcaram o Brasil no período) que Simonsen desempenhou suas atividades intelectuais de forma mais marcante, abrindo a discussão sobre o problema do subdesenvolvimento que afetava o Brasil e outras nações da América Latina e do Mundo.

Neste sentido, Edgar Carone (1971) apresenta a obra de Simonsen como dividida em dois períodos: antes e depois de 1930, sendo que na primeira etapa este autor considera as questões e teses apresentadas por Simonsen mais ligadas ao seu mundo particular, ainda que tenham importância histórica; após 1930, suas obras ganham o vulto que hoje se reconhece.

Grosso modo poderíamos dividir a sua obra em dois momentos básicos: antes e depois de 1930. A divisão se justifica porque no primeiro período seus trabalhos se relacionam mais com problemas específicos de sua profissão: a Prefeitura de Santos, o calçamento em São Paulo, a carne e pastagens no Brasil, missão à Inglaterra, a função dos homens de negócio, etc. Algumas questões teóricas já aparecem expostas em $\mathbf{O}$ trabalho moderno ou no discurso de inauguração do Centro das Indústrias do Estado de São Paulo, mas o que predomina são problemas imediatistas, preâmbulo à obra que irá realizar na segunda fase. (CARONE, 1971, p.24, grifo do autor).

Por sua vez, Vera Cepeda (2004) divide as obras de Simonsen em três momentos, destacando a importância de cada um deles em relação ao tempo em que foram desenvolvidas (de 1913 a 1948) e destacando o que entende ser uma mudança no pensamento do autor em estudo, que inicialmente teria defendido posições mais liberais e em conciliação com os cafeicultores para, em um segundo momento, migrar para a implantação do industrialismo e, em um terceiro momento, defender a planificação e a intervenção estatal na economia como forma de dirimir os conflitos.

\footnotetext{
Para demarcar as fases que se sucedem na obra de Simonsen procuramos identificar duas ordens de fatores que combinados indicam uma ruptura conceitual: a mudança dos temas tratados ou a alteração significativa do tratamento dado a eles. Com base nesses dois critérios é possível detectar três fases na obra do autor: fase I (aliança indústria - café); fase II (primeira ruptura - afirmação da industrialização); fase III (segunda ruptura - o projeto nacionalista). Nas três há uma mudança significativa das peças angulares do discurso e também uma variação no campo ideológico apresentado pela obra. Assim, na primeira fase predomina a filiação ao liberalismo econômico e a submissão ao arco de alianças do liberalismo político tal qual o praticado na Primeira República; na segunda há um deslocamento crescente para as posições corporativas, com a aproximação do governo de Vargas e com a recusa dos desvios individualistas; e, na terceira, a manutenção do viés intervencionista mesclado com a recusa ao modelo orgânico do Estado Novo (uma posição precursora do planejamento desenvolvimentista). Mas o dado mais interessante sobre as rupturas é que elas formam-se na corrente subterrânea do pensamento simonseano, na passagem do empresário para o intelectual. (CEPEDA, 2004, p.160).
}

Destacando a importância da obra de Simonsen pelo viés econômico, Mendonça (2010) aponta que a releitura de "História Econômica do Brasil", de Simonsen, teria levado Celso Furtado, um dos mais importantes teóricos brasileiros, a se inspirar na formulação de sua principal 
obra, "Formação Econômica do Brasil", onde Simonsen fora citado por Furtado exatas onze vezes (sendo que somente sete autores brasileiros foram utilizados por Furtado nesta obra). Ainda, Bielschowsky (2000) aponta que Simonsen foi pioneiro no pensamento desenvolvimentista, abrindo o debate sobre importantes questões que somente anos depois foram mais bem elaboradas pela CEPAL, tais como o subemprego, o estruturalismo e outras problemáticas.

Por fim, Colistete (2007) afirma que o pensamento do economista argentino Raúl Prebisch, fundador e um dos principais formuladores da CEPAL, criada em 1949, sendo, inclusive, o autor do texto que historicamente ficou conhecido como o "Manifesto da CEPAL", foi muito bem recebido pelos industriais quando de seu lançamento, inaugurando uma nova fase na busca pela industrialização brasileira, uma vez que recuperava os argumentos historicamente defendidos pela entidade nas décadas anteriores, formulados pro Simonsen.

De fato, as teses cepalinas juntaram-se às idéias de Friedrich List, Michail Manoilescu do próprio expoente dos industriais paulistas, Roberto Simonsen, idéias essas que haviam dado suporte à atuação dos industriais em diversas instâncias de governos e da sociedade (COLISTETE, 2007, p. 03)

Há, ainda, outras importantes menções e diálogos que completam o presente trabalho e que nos ajudam a compreender a dimensão do pensamento de Roberto Simonsen para a construção do projeto industrial brasileiro, que acabou se consolidando anos depois de sua morte. Entre estes temas e autores, destacamos as contribuições de Del Vecchio e Diéguez (2008), que resgataram as fundamentais contribuições de Simonsen para a consolidação da sociologia aplicada no Brasil, especialmente quando da fundação da Escola Livre de Sociologia e Política, que tinha currículo, metodologia e professores voltados para a pesquisa dos problemas brasileiros, destacando-se as pesquisas sobre as condições de vida dos trabalhadores urbanos de São Paulo nos anos 1930.

Ainda, os trabalhos de Maurilio Rompatto (2004), que trata do tema do protecionismo e sua importância nas ideias de Simonsen, bem como os de Artur Aquino (2010), que trabalhou com hipótese próxima a deste trabalho, mas analisando as discussões acontecidas no I Congresso Brasileiro de Economia, de 1943. Por fim, importante destacar os trabalhos de Maza (2004), Heitor Ferreira Lima (1963 e 1976), e Cyro Berlink (1948 e 1964) que também se dedicaram a estudar as ideias de Roberto Simonsen; de Marisa Saenz Leme (1976), cujos estudos sobre os empresários industriais embasaram nossos estudos anteriores e atuais, bem como trabalhos de nossa autoria (2013a, 2013b e 2015), entre outras inúmeras contribuições.

Retomando as ideias de Simonsen, em nosso entendimento, o tema do desenvolvimento como forma de superação da pobreza possui importância central para o autor, sua obra e sua atuação. É trabalhando esta questão que Simonsen se depara, em 1919, com as precárias condições de vida dos operários da Companhia Construtora de Santos, o que o levou a construir um bairro popular, a Vila Belmiro; é a melhor qualidade de vida dos trabalhadores europeus e 
americanos, por ele testemunhadas nas missões comerciais, que chamam a atenção do autor para o fato de que, nos países desenvolvidos, ainda que não fossem ricos os operários mantinham um padrão de vida muitas vezes superior aos correlatos nacionais.

Da mesma forma, é a busca pela superação da pobreza que o levará aos históricos e importantíssimos debates com os liberais na década de 1940, oportunidade na qual o autor apresenta, de maneira pioneira, a tese do subdesenvolvimento, que se tornaria, a partir de 1949, com a publicação do Manifesto da Cepal, o marco dos estudos econômicos realizados no Brasil e em toda a América Latina. É ainda por conta das condições de vida que o autor formula suas teses sobre a relação entre padrão de vida e industrialização, bem como toma contato com a sociologia, na qual via um método eficaz para determinar o ganho médio que um trabalhador precisaria ter para sua existência "digna", como dizia Simonsen.

Logo, o tema das condições de vida e de sua superação pelo desenvolvimento econômico industrial aparece em todas as fases do pensamento de Simonsen ao longo de sua carreira intelectual e prática, que caminham pari passo em sua trajetória de vida.

E é exatamente a construção destas teses, ao mesmo tempo em que liderou a classe industrial brasileira neste período, seja como presidente da CIESP, fundador da CNI, Deputado, Senador, fundador do SESI e do SENAI e outros órgãos e instituições relacionados à indústria, que ao nosso ver permitiu que a classe industrial brasileira se firmasse enquanto tal, podendo disputar a hegemonia econômica e política que almejava tendo como base ideológica um arcabouço de ideias sobre como o Brasil deveria conduzir, através do Estado, sua industrialização.

E tais ideias, que transcenderam a Roberto Simonsen a fim de se tornarem parte do projeto industrialista nacional, também conferem ao autor e sua obra importância fundamental. Esta consolidação de ideias e, mais precisamente, a simbiose delas com o governo de Getúlio Vargas e o Estado, deu-se no I Congresso Brasileiro de Economia, presidido pelo próprio Presidente da República e palco da união política que deu à indústria o status de força política e econômica do Brasil daquele período.

Neste sentido, apresentaremos os discursos proferidos por Roberto Simonsen, pelos industriais brasileiros, e de Alexandre Marcondes Filho, então Ministro do Trabalho de Getúlio Vargas (que não usou a palavra na ocasião), a fim de demonstrar como estavam próximos os pensamentos dos industrias e do Estado naquele momento, com o segundo praticamente encampando como suas as propostas dos industriais, através da conversão das mesmas em "objetivos da democracia brasileira" que somente seriam alcançados pela "união de todos os interesses" em torno do desenvolvimento do Brasil, ou em outras palavras, como o Estado iria converter em políticas estatais a ideologia industrial. 
Ainda, apresentaremos parte da estrutura do I Congresso, seus participantes e teses, a fim de contextualizar a importância do evento e, principalmente, o momento em que as ideias de Simonsen deixam de representar seus pensamentos sobre o papel da indústria e passam a representar o pensamento da indústria sobre seu papel e o do Estado na construção de sua hegemonia econômica e política.

Feitas estas considerações iniciais, passemos a analisar o papel do I Congresso da Indústria na consolidação da classe industrial brasileira no período de 1940.

\section{Congresso Brasileiro da Indústria: união entre Estado e burguesia industrial}

O I Congresso Brasileiro da Indústria aconteceu de 08 a 14 de dezembro de 1944. Em nosso entendimento, o objetivo do Congresso era fixar uma base de propostas da classe industrial brasileira, seus anseios e intenções para a economia brasileira e o papel do Estado em relação a este ramo econômico. Este conjunto de proposta, entendemos, tinha o propósito de consolidar a classe industrial como força hegemônica, tanto na economia quanto no Estado, com a ocupação dos postos técnicos e políticos de formulação e decisão acerca das políticas econômicas.

$\mathrm{Na}$ busca destes objetivos, que a indústria já vinha perseguindo há décadas, a classe industrial brasileira mobilizou-se. Foram apresentadas 137 teses, versando sobre temas os mais variados sobre o desenvolvimento da indústria brasileira, desde o modo de organização da produção até a planificação da economia, passando pelas relações de classe com o operariado e sua qualificação, a legislação trabalhista e social, entre outros temas. Participaram do Congresso 324 congressistas, representando 191 entidades, que variam entre sindicatos, órgãos estatais, indústria propriamente ditas e outros, de todo o Brasil.

Ao todo, sete comissões técnicas foram montadas para diagramar as propostas apresentadas e aprovada, sendo a primeira Comissão a de sistematização e as demais debatendo planificação econômica; reajustamento da produção industrial para o período pós-guerra; fatores de encarecimento da produção industrial; normas para harmonização entre as classes; fibras nacionais.

Para compor a Segunda Comissão, responsável pela formulação das propostas de caráter político-econômico, foram escalados Roberto Simonsen e Cyro Berlink, além de Álvaro de Souza Lima, João Luderitz e outros 27 membros. Foi nesta Comissão que Simonsen, que também presidiu a Comissão Técnica e de Redação e foi o Vice-Presidente do Congresso (presidido por Evaldo Lodi), apresentou as teses "Planificação Econômica do Brasil" e "O conceito de renda nacional e sua influência na relação dos padrões de vida. Cooperação econômica entre as nações. 
Medidas para auxiliar na elevação dos níveis de vida nos países pobres”, sobre as quais debateremos a seguir, mas que foram aprovadas e fizeram parte da redação final de propostas.

Da parte do Governo Federal, é de especial atenção anotar que o Congresso foi presidido pelo próprio Getúlio Vargas e contou com a presença de diversas autoridades federais de então, entre elas o Ministro do Trabalho Alexandre Marcondes Filho, o Interventor do Estado de São Paulo Fernando de Souza Costa, entre outros, apontando para a existência de uma aliança da burguesia industrial com o Governo Vargas com o objetivo de influenciar a formulação da política econômica que melhor lhe conviesse.

Outra importante questão a ser notada é que o Congresso acontecia em um momento que os industriais, principalmente Roberto Simonsen, entendiam ser crucial para o desenvolvimento industrial brasileiro: planejar o setor para o pós-II Guerra. Após experimentar considerável expansão durante o conflito, quando o Brasil se viu premido pela necessidade de substituir as importações (que estavam voltadas para a Guerra), bem como ampliar sua produção industrial para também se aproveitar economicamente da situação exportando para os países centrais, o fim da II Guerra poderia significar um problema para a jovem indústria brasileira e também latinoamericana.

Em trabalho sobre o tema (2013), debatemos como Simonsen levantou teses a respeito do que deveria ser feito pelo Brasil para evitar que os países desenvolvidos custeassem sua recuperação econômica às custas do rebaixamento das economias latinas, redesenhando a divisão internacional do trabalho e relegando às periferias do então Terceiro Mundo a condição de importadores dos manufaturados que a Europa voltaria a produzir, em troca de lhes exportar as matérias-primas.

O I Congresso deu-se antes das teses de Simonsen a respeito do tema, mas a preocupação sobre como o Estado e a indústria deveriam se comportar já estava presente no evento. Em especial, permeou as propostas dos congressistas a questão do planejamento econômico do Estado para a indústria, solução pensada e defendida pelas entidades industriais como forma de resolver dois problemas que entendiam ser centrais: 1) o desenvolvimento definitivo da indústria enquanto atividade econômica principal da economia nacional, com o incentivo e a proteção do Estado; 2) a solução para a pobreza, que era entendida como geradora de conflitos econômicos e políticos entre as classes e se constituía em uma ameaça à democracia brasileira.

É neste sentido que o discurso de Roberto Simonsen na abertura do Congresso, em substituição ao presidente Evaldo Lodi (que, segundo consta nos anais, não chegara em tempo ao evento de abertura), apontou logo de início que a intenção das classes industriais brasileiras era criar uma "consciência coletiva" acerca dos "principais anseios na ordem econômica e social" dos 
industriais brasileiros, os quais considerava a mais bem organizada, do ponto de vista político, segmento social do Brasil. (SIMONSEN, 1945, p.71).

Afirmou, ainda, que na visão da classe industrialista, o Brasil não necessitava de políticas econômicas que resultassem em conflito, mas sim de propostas que pudessem elevar o nível de vida nacional, “...edificando uma civilização [...] onde o homem, $[. .$.$] tenha uma existência digna e$ livre, e na qual a Nação possa atingir a um necessário grau de progresso, governada por diretrizes democráticas, subordinadas aos preceitos cristãos” (SIMONSEN, 1945, p. 74).

Já em relação à renda nacional, Simonsen ressalta a importância do tema, tomado como chave para o progresso material brasileiro, uma vez que, no entender dos industriais, seria incompatível a convivência de crescimento econômico com pobreza. Nestes termos, sugere que o Brasil adote o mesmo critério para medir seu crescimento econômico que outros países desenvolvidos já fazem, através do padrão de vida da população, que a seu ver deveria ser cientificamente determinado. O conceito, enquanto soma, englobaria ainda o lucro empresarial e a poupança nacional.

E esta renda não deveria ser imposta por decreto, mas sim ser o resultado material da elevação do trabalho e da produtividade, que só poderiam ser alcançados com a organização e a promoção do Estado. De igual forma, a condição de vida dos trabalhadores também precisaria mudar, devendo-se garantir condições mínimas de eficiência, saúde e alimentação, bem como os melhores equipamentos, de modo a ampliar sua produtividade.

Em seu âmbito executivo, é dada, porém, ao poder público, a oportunidade de exercer uma ação decisiva, não só agindo nos campos de trabalhos julgados essenciais ao progresso da nação e que não tenham podido despertar a iniciativa particular, como também promovendo a criação e o fortalecimento de uma grande série de fatores favoráveis a um maior surto de trabalho nacional. (SIMONSEN, 1945, p. 75)

Tal patamar seria alcançado, de acordo com Simonsen, por meio da planificação da economia, cuja finalidade seria a de afinar os esforços econômicos industriais tendo por objetivo acelerar o aumento da renda nacional. Em seu entendimento, a planificação não seria antidemocrática, pois se trataria de uma grande união nacional, englobando todas as atividades econômicas, os sindicatos, as associações e seus representantes, que auxiliariam na elaboração e execução do Plano. (SIMONSEN, 1945, p. 77)

Foi nestes termos que Simonsen apresentou a Getúlio Vargas as principais propostas e reivindicações da indústria, buscando claramente o apoio do Estado brasileiro e do próprio Vargas para ver realizadas as intenções da classe industrial de se tornar a força hegemônica na economia e na política do Brasil dos anos 1940 e seguintes. Vale, portanto, lermos nas palavras do próprio Roberto Simonsen os termos e intenções desta relação: 
A presença de Vossa Excelência e de tão altas autoridades do Governo da República e do Estado nesta sessão inaugural constitui, sem dúvida, um poderoso estímulo para que intensifiquemos os nossos esforços, no patriótico desejo de colher os melhores frutos para o progresso da nação.

Pode Vossa Excelência estar certo de que, olhos fitos na grandeza do Brasil, na harmonia de seus filhos, na atmosfera de ordem e paz necessária ao desenvolvimento do seu grande destino, não serão aqui consideradas as legítimas aspirações patronais e trabalhistas, de cuja conciliação, tão grata ao civismo de Vossa Excelência, depende da realização gloriosa desse destino. (SIMONSEN, 1945. P. 80)

Em seguida a Simonsen, usou a palavra o Ministro do Trabalho Alexandre Marcondes Filho, que falou em nome do Governo Federal. Logo de início, ressaltou as medidas que o governo havia adotado para preparar o Brasil para o novo período que se iniciava, sempre considerando o equilíbrio entre as classes e a articulação entre elas, de modo que o Brasil adotasse uma postura e uma política consonante com o momento que o mundo estava vivendo. (MARCONDES, 1945, p. 82)

Entre as medidas relatadas pelo Ministro, estava a criação do Conselho Nacional de Política Industrial e Comercial, com o objetivo de planejar as medidas econômicas necessárias para adaptar o Brasil no após-guerra, dentre elas a defesa e o fomento das forças industriais, a produção de matérias-primas, as indústrias de base e outras, como forma de proteger os interesses e a economia nacionais.

Pelo que informou o ministro em seu discurso, fica claro que os interesses "nacionais" são, na verdade, os interesses industriais: protecionismo, produção de matérias-primas, indústria de base, equilíbrio entre as classes, enfim, uma espécie de síntese das principais propostas do Congresso, revelando ainda o grau de intersecção entre Governo e industriais já em 1944.

Mesmo a questão do cálculo da "renda nacional" já estaria em andamento, por estudos comandados pelo próprio Simonsen e executado pelo então Serviço de Estatística do Ministério do Trabalho, que concluiu ser a renda nacional (que entendemos ser uma prévia do que viria a ser o Produto Nacional Bruto - PNB) algo em torno de CR $\$ 40$ bilhões. A proposta dos industriais, aceita pelo Governo, era planejar o crescimento industrial e econômico brasileiro de modo a alcançar, nos 10 a 15 anos posteriores, a cifra de CR 200 bilhões de renda nacional, um crescimento que o Ministro entendia possível e adequado para travar a "guerra ao pauperismo", desde que não se contasse com crescimento natural da economia, mas sim com seu estímulo através de financiamentos e outras técnicas de aceleração, a serem buscadas pelo Estado. (MARCONDES, 1945, p. 84)

Nestes termos, a planificação da economia proposta por Simonsen em nome dos industriais e aceita pelo Governo tinha por objetivos 
populações e prover o país de uma estruturação econômica e social forte e estável, fornecendo à Nação os recursos indispensáveis à sua segurança e a à sua colocação em lugar digno na esfera internacional. (MARCONDES, 1945, p. 84)

Pouco a pouco, mas em curto espaço de tempo, o projeto industrialista tornou-se a força econômica e política hegemônica no Brasil dos anos 1940 e nas décadas seguintes, ocupando postos políticos e técnicos no Executivo e moldando as políticas estatais voltadas para a economia e suas agendas. É emblemática, neste sentido, a parte do discurso do Ministro Marcondes Filho em que o mesmo ressalta que as propostas de planificação da economia e elevação da renda nacional são os fundamentos da "democracia econômica e social" brasileiras:

Por sua vez, a Secretaria do Conselho estudou o plano como técnica neutra, aplicável no Brasil, para formar o arcabouço da democracia econômica e social, que é fundamento da legítima democracia política. [...] O plano é um estádio do conhecimento, nesta era de complexidade e da interdependência industrial, permitindo antever os efeitos e aplicar os seus elementos fundamentais estrategicamente, isto é, política e plasticamente, já que a sociedade nunca pode ser "estabelecida" segundo um modelo predeterminado e invariável. (MARCONDES, 1945, p. 85)

É interessante notar, ainda, que não obstante o planejamento econômico e o combate ao pauperismo fossem propostas das classes industriais, portanto com claro viés ideológico, sua aceitação e implementação pelo Estado não poderia se dar nestes termos, sendo mais aceitável que sua adoção se desse como certeza científica, como verdade estudada e apurada. Não seria nem "dirigismo" nem uma "guerra predatória", mas um ponto de equilíbrio capaz de reorganizar a economia nacional para as novas necessidades daqueles tempos - a indústria.

A planificação foi concebida, no anteprojeto, como um controle dos efeitos de cada atividade sobre as outras esferas, pelo conhecimento de sua interdependência, condição que permite influir nos pontos estratégicos da vida econômica e social, através de técnicas cuja aplicação independe de ideologias, podendo ser, como mostrou a Comissão, fundando-se nas melhores autoridades, um legítimo instrumento de organização para a democracia e a liberdade. No nosso caso, essas técnicas visam aumentar num ritmo acelerado a produtividade do trabalho e, assim, a renda nacional, para elevação do nível de vida do brasileiro, através de um sistema de distribuição das oportunidades que assegure a Justiça Social e lastreie a democracia brasileira. (MARCONDES, 1945, p.8687)

Há mais elementos unindo Estado e indústria nesta aliança hegemônica. O órgão criado para combater a pobreza, o "Gabinete de Guerra ao Pauperismo", seria presidido pelo próprio presidente Getúlio Vargas e composto pelos demais Ministros e também por membros da sociedade, no caso os representantes da classe industrial brasileira. Os Anais do Congresso não trazem maiores informações sobre a formação do referido órgão e nem sobre sua composição, nem encontramos registros outros de seu funcionamento.

Mas, a indicação, pelo Ministro, na abertura do Congresso Brasileiro da Indústria, de que o Estado transformaria em política pública as duas principais ideias da classe industrial brasileira 
acerca do desenvolvimento econômico nacional permite concluir que o plano de se tornar a força motriz nacional dos industriais brasileiros foi exitoso. E o caminho da conquista passou pelo desenvolvimento das propostas econômicas de desenvolvimento nacional e diminuição da pobreza inicialmente formuladas por Simonsen e que depois transformaram-se em bandeiras da classe industrialista.

Uma vez acontecida a intersecção entre as ideias de classe e o Estado, o desenvolvimento econômico e social por meio da industrialização deixou de ser uma proposta segmentada para se transformar em um "objetivo da democracia brasileira", ao menos nos dizeres do Ministro Marcondes Filho:

\begin{abstract}
A nossa época é, por força mesmo da evolução industrial, uma era de democracia substancial. Evidentemente este conceito não se limita a uma forma de democracia puramente jurídica, que pensadores do século dezoito, antes da época industrial, criam aplicável a todos os povos e a todas as épocas. Muito ao contrário, ele se liga ao conceito estrutural da realidade econômica e social, e ao próprio conceito de plano, vivendo o clima político do fato histórico único individual que nos cabe e que se revela como uma forma que até agora não surgira. A democracia contemporânea, já afirmei aqui mesmo, quer dizer iguais oportunidades, com a segurança de direitos mínimos, não só políticos e civis, mas econômicos e sociais e participação de todo o povo nas atividades coletivas. (MARCONDES, 1945, p. 88)
\end{abstract}

O ingresso do Brasil na era moderna, portanto, seria por meio da industrialização. Mas o modelo de participação política e social não seria o mesmo adotado na Europa, mas um desenvolvido especialmente para nossa situação política, a doutrina da paz social, em que basicamente o Estado atuaria como mediador do conflito entre as nascentes classes econômicas, editando leis que pudessem equilibrar as desigualdades financeiras então existentes.

No caso em especial, a preocupação dos industrias com a pobreza tinha um duplo viés: ao mesmo tempo em que ela inviabilizava o capitalismo industrial, também a carestia era uma fonte vigorosa de conflitos sociais que, ao entender de Simonsen, dos industriais e também do Governo, mais atrapalhavam do que ajudavam à aceleração do desenvolvimento econômico e social por eles pretendidos. Enquanto houver pobreza, reafirmava o Ministro em seu discurso, a democracia não existirá enquanto salvaguarda de iguais oportunidades para todos. (MARCONDES, 1945, p. 89).

Essa era, também, a ideia de Simonsen. Em "Desenvolvimento Econômico e Condições De Vida: a Força de uma ideia e uma ideia força na obra de Roberto Simonsen", de 2014, pudemos debater o quanto o empresário/intelectual se debateu com o conceito de condições de vida e como ele aparece como um dos eixos centrais de suas obras, ora combinando com suas teorias econômicas, ora com as sociológicas, bem como com as de Direito Internacional (estas voltadas para a cooperação dos povos pela supressão da pobreza, uma obra incompleta).

Em nosso entender, o tema das condições de vida é uma das ideias força do pensamento de Simonsen: sem aumentar o padrão de vida dos trabalhadores até o ponto em que eles pudessem 
subsistir e integrar o próprio mercado consumidor, o Brasil não se consolidaria como nação independente. Este não era o único passo a ser dado em tal direção, mas era um deles, parte importante de um circuito de ideias que, na expectativa de Simonsen, elevariam o Brasil à condição de país desenvolvido.

Neste sentido, em “As Finanças e a Indústria” (1931), Simonsen reforça seus argumentos a favor da industrialização como forma de elevação do padrão de vida, chamando a atenção para o fato de que o Brasil estava atrasado em relação aos países centrais porque não possuía elementos de racionalização capazes de propor e executar soluções para os problemas nacionais.

[...] somos um povo de fraca produtividade. Trabalhamos pouco e com pequena eficiência, sendo aqui mínimo o rendimento médio por cabeça. [...] não temos, praticamente, capitais próprios e nem economias. É impressionante a pobreza do nosso povo. Quem viaja pelo interior do país, quem visita a casa do caboclo, mesmo nos arredores de São Paulo, não deixa de ficar impressionado como um ser humano, no ano de 1931, se satisfaz com uma tapera de barro esburacada, coberta com sapé, tendo o chão de terra dura por piso e tarimbas, bancos toscos e esteiras por mobiliário. A alimentação do nosso homem de campo é rudimentar e insuficiente. Como se justifica que na época atual seja este o padrão de vida desse nosso homem com todas as consequiências decorrentes desse atraso? (SIMONSEN, 1931, p.40).

A solução para a pobreza seria, então, a adoção da indústria como base econômica nacional, adotando o mesmo método de desenvolvimento dos outros países:

É numa política industrial fundada em bases racionais adequadas às condições de nosso meio que teremos que ir buscar, principalmente, a produção dos valores em bens sociais de que necessitamos para o rápido aumento de nosso poder aquisitivo e porque não dizêlo, com os benéficos reflexos de adiantamento de processos de trabalho que a industrialização sempre conduz (SIMONSEN, 1931, p.41).

O conceito de "padrão de vida", na visão de Simonsen, seria o centro da ordem econômica, pois seria a condição para tanto para o desenvolvimento econômico e humano do Brasil como também seria o mais próximo possível da liberdade, que não aconteceria, segundo Simonsen, enquanto a pobreza permanecesse como fonte maior da desigualdade. Em outras palavras, a liberdade econômica estaria condicionada à elevação e manutenção de um padrão de vida digno.

Entendemos ser esta uma passagem crucial para a compreensão do pensamento e da estratégia de Simonsen: quando foi deputado na Assembleia Constituinte de 1934, apresentou e fez aprovar a inclusão do tema das condições de vida no texto constitucional sobre a ordem econômica, fazendo constar da Constituição que a manutenção de um padrão de vida digno seria um ideal a ser buscado pelo Estado brasileiro. O próprio autor, na obra "Níveis de Vida e a Economia Nacional”, de 1940, seis anos após sua passagem pelo Congresso Nacional, declarou que sua intenção com a inserção do conceito de padrão de vida na Constituição de 1934 era, de fato, fomentar o debate sobre o tema: 
Pela primeira vez, na carta constitucional de um país, em 1934, por sugestão minha, representante que era das classes patronais de São Paulo, se fez incluir a obrigação do levantamento periódico, por parte dos poderes públicos, dos níveis de vida nas várias regiões do país. Justificando tal iniciativa, acentuei a necessidade de terem os governantes constantemente sob seus olhos a carta das condições de vida das populações, afim de que constituísse sua constante preocupação, o emprego de todos os meios adequados e possíveis à sua melhoria (SIMONSEN, 1940, p.15).

Notemos duas questões importantes deste movimento: 1) a ideia partiu de um integrante da burguesia, não do proletariado; 2) em 1934, a agricultura era a força econômica e política hegemônicas no Brasil e a indústria lutava para se firmar, optando por estratégia a formulação de um conjunto de ideias-força, de uma base ideológica própria, portanto, para se diferenciar da agricultura e disputar com ela o controle do Estado e da economia.

\section{Pioneiro do projeto industrialista brasileiro}

Por todo o até aqui exposto, podemos afirmar que as ideias e a atuação de Simonsen possuem a importância fundamental de ser a versão pioneira dos objetivos que se tornaram o próprio projeto industrialista brasileiro, ao serem incorporadas pelo conjunto da classe ao longo da década de 1930, até se tornarem a representação do que pensava a burguesia industrial dos anos 1940 e 1950, quando sua hegemonia política e econômica sacramentou-se, sendo esta a síntese do que queremos apresentar neste artigo: Simonsen foi o pioneiro no desenvolvimento do projeto industrial brasileiro e suas ideias tornaram-se as ideias da classe industrial, foram por ela incorporadas na condição de ideologia, descolando-se da pessoa de seu idealizador para representar um projeto político de poder da nascente burguesia industrialista.

Ao afirmar que a pauperização precisaria ser superada, a fim de que o Brasil pudesse se estabilizar socialmente; ainda, que a pobreza só seria superada pela industrialização; e por fim, que a industrialização só seria plenamente implantada com a planificação da economia pelo Estado, Simonsen construiu os alicerces onde se ergueu o projeto industrialista brasileiro e, arriscamos afirmar, a própria identidade de classe burguesa nacional, que ao instituir como suas um corolário de ideias acerca do Brasil e de seu próprio papel na construção da economia nacional, se estabeleceu como força política perante o Estado e perante o proletariado, que foi integrado "por cima" ao projeto, na crença de que o desenvolvimento industrial o beneficiaria.

Por fim, uma última reiteração a fim de deixar claro um ponto que entendemos importante: a incorporação das ideias de Simonsen pela classe industrial brasileira não se deu somente como tática, como caminho para alcançar objetivos - portanto descartáveis, mas sim como ideologia de classe, ideias que pautaram sua atuação política e permitiram sua chegada ao poder e, mais do que isso, implantar em partes estas ideologias. 
É certo que o setor industrial tinha interesses financeiros neste processo, mas o centro de sua atuação e de seu lucro não estavam na forma como a indústria seria tratada pelo governo, mas sim em direcionar as ações do Estado em seu favor, fazendo com que seus objetivos se tornassem os mesmo da "democracia", da "ordem econômica" e outros, como vimos ao longo do trabalho, em uma escala de profundidade que extrapola, em nosso ver, a possibilidade de os industriais terem agido sem base ideológica e sem que os conceitos já aqui apresentados tenham sido este alicerce.

Esta é, portanto, a hipótese que apresentamos, baseados nos muitos indícios de que as ideias de Simonsen foram incorporadas pela burguesia industrial em seu projeto, tornando-se sua representação ideológica junto à sociedade, dando a tais ideias, portanto, um viés institucional que transcende a obra intelectual de seu autor, ao mesmo tempo em que as promove ao patamar de um pensador brasileiro ainda a merecer o devido reconhecimento. 


\section{Referências}

ANAIS DO I CONGRESSO BRASILEIRO DA INDÚSTRIA. São Paulo: CNI/FIESP, 1945.

AQUINO, Artur. I Congresso Brasileiro de Economia 1943: atores, intelectuais e ideologias na constituição de uma consciência de classe entre os industriais e a consolidação do projeto industrialista. In PLURAL, Revista do Programa de Pós-Graduação em Sociologia da USP, São Paulo, v.17.1, 2010, pp.59-88.

BERLINK, CYRO. Roberto Simonsen: a indústria, as ciências sociais e a realidade brasileira. São Paulo: Escola Livre de Sociologia e Política de São Paulo, 1948.

Comemorações do $40^{\circ}$ aniversário da Escola de Sociologia e Política de São Paulo. Ciências Políticas e Sociais, São Paulo, v.2, nº 3, setembro de 1964.

. Liderança e liberdade. Revista Sociologia - Revista dedicada à teoria e à pesquisa nas ciências sociais. São Paulo: Sociologia e Política, vol. 26, setembro de 1964, p. 281-305

BIELSCHOWSKY, Ricardo. Pensamento Econômico Brasileiro. O ciclo ideológico do desenvolvimentismo. $4^{\text {a }}$ edição, Rio de Janeiro: Contraponto, 2000.

CARONE, Edgard. Roberto C. Simonsen e sua Obra. RAE - Revista de Administração de Empresas. Rio de Janeiro: 11(4): p.23-28, out/dez de 1971.

. O pensamento industrial no Brasil. 1880-1945. Rio de Janeiro/São Paulo: Difel, 1977.

CEPEDA, Vera. Roberto Simonsen e a formação da ideologia industrial no Brasil: limites e impasses. 2004. Tese. (Doutorado em Ciência Política) - Faculdade de Filosofia, Letras e Ciências Humanas, Universidade de São Paulo, São Paulo.

. Estado, Democracia e Nação na teoria do subdesenvolvimento. Trabalho apresentado no XII Encontro Nacional de Economia Política, junho de 2007. Disponível em: $<$ http://www.sep.org.br/artigo/_861_d4b012a6ed845f6bac443e6cd55e34a7.pdf>. Último acesso em 30 de set. de 2009.

O problema do moderno no pensamento de Roberto Simonsen: crítica ao liberalismo e a questão nacional. In: XV Congresso Brasileiro de Sociologia, 2011, Curitiba. Anais do XV Congresso Brasileiro de Sociologia, 2011, sem paginação.

COLISTETE, Renato Perim. A força das idéias: a CEPAL e os industriais paulistas na primeira metade da década de 1950. in História Econômica \& História de Empresas, vol. X , 2006, p. 123153.

FREITAS, Moacir Jr. Um Plano Marshall para a América Latina: a contribuição de Roberto Simonsen para a tese do subdesenvolvimento latino-americano. In XXIX CONGRESSO LATINOAMERICANO DE SOCIOLOGIA - ALAS, Chile, 2013. Disponível em http://actacientifica.servicioit.cl/biblioteca/gt/GT17/GT17_DeFreitasJunior.pdf, acessado em 05 de fevereiro de 2017.

Desenvolvimento Econômico e Condições de Vida: a força de uma ideia e uma ideia força na obra de Roberto Simonsen. Publicatio UEPG Ci. Soc. Apl., Ponta Grossa, 21 (2): 161172, jul./dez. 2013. 
. Roberto Simonsen, as condições de vida dos trabalhadores e o projeto industrialista brasileiro. $39^{\circ}$ Encontro Anual da ANPOCS, outubro de 2015. Disponível em www.anpocs.org.br, acessado em 05 de fevereiro de 2017.

IANNI, Octávio. Estado e Capitalismo. $2^{\mathrm{a}}$ ed. Editora Brasiliense: São Paulo, 1989.

LEME, Marisa Saens. A Ideologia dos Industriais Brasileiros (1919-1945). Petrópolis: Vozes, 1978.

LIMA, Heitor Ferreira. Mauá e Roberto Simonsen: dois pioneiros do desenvolvimento. São Paulo: Edaglit, 1963.

Três industrialistas brasileiros: Mauá, Rui Barbosa, Roberto Simonsen. São Paulo: AlfaÔmega, 1976.

MARCONDES, Alexandre. "Discurso de abertura do I Congresso Brasileiro da Indústria". ATAS DO I CONGRESSO BRASILEIRO DA INDÚSTRIA, São Paulo, CNI/FIESP, 1945.

MAZA, Fabio. O idealismo prático de Roberto Simonsen. São Paulo: Fiesp, 2004

MENDONÇA, Marina Gusmão. A formação intelectual de Celso Furtado. In: Corsi; Camargo (org). Celso Furtado: os desafios do desenvolvimento. SP: Cultura Acadêmica; Marília: Oficina Universitária, p. 01-20, 2010.

PREBISCH, Raul. O Desenvolvimento Econômico da América Latina e seus principais problemas. Revista Brasileira de Economia, Vol. 3, nº 3, 1949.

ROMPATO, Maurílio. Roberto Simonsen e a evolução sem revolução. 2004. 384p. Tese (Doutorado em História) - Unesp, Assis, 2004.

SIMONSEN, Roberto. "Discurso de abertura do I Congresso Brasileiro da Indústria". Atas do I Congresso Brasileiro da Indústria. São Paulo, CNI/FIESP, 1945.

. Orientação industrial brasileira. São Paulo: São Paulo Editora Ltda, 1928.

. As crises no Brasil. São Paulo: São Paulo Editora, 1930.

. A construção dos quartéis para o Exército. São Paulo: sem editora, 1931.

. As finanças e a indústria. São Paulo: São Paulo Editora, 1931.

. À margem da Profissão - discursos, conferências e publicações. São Paulo: São Paulo Editora, 1932.

. Rumo à verdade. São Paulo: São Paulo Editora, 1933.

. Ordem econômica, padrão de vida e algumas realidades brasileiras. São Paulo: São Paulo Editora, 1934.

1939.

. A evolução industrial do Brasil. São Paulo: Empresa Gráfica da Revista dos Tribunais, 
Niveis de vida e a economia nacional. São Paulo, sem editora, 1940.

Recebido em: 18-03-2017;

Revisado em: 02-05-2017;

Publicado em 04-05-2018. 